\title{
Assessing Strengths and Weaknesses in Solving Work Problems: A Knowledge and Appraisal Personality Architecture (KAPA) Analysis of the Trait Conscientiousness and Self-Efficacy
}

\author{
Daniele Artistico $^{1}$ \& Arielle M. Rothenberg ${ }^{1}$ \\ ${ }^{1}$ Baruch College, The City University of New York, NY, USA \\ Correspondence: Daniele Artistico, 1 Baruch Way Department of Psychology, Baruch College, The City \\ University of New York, New York, NY, 10010, USA. Tel: 1-646-312-3837. E-mail: \\ daniele.artistico@baruch.cuny.edu
}

Received: June 8, $2013 \quad$ Accepted: July 12, $2013 \quad$ Online Published: August 8, 2013

doi:10.5539/ijps.v5n3p84 URL: http://dx.doi.org/10.5539/ijps.v5n3p84

\begin{abstract}
Our goal was to demonstrate the effect of personal strengths and weaknesses when solving work related problems among students enrolled in business courses. We predicted that each participant would uniquely activate personal knowledge (such as strengths and weaknesses) in situations idiosyncratically judged as relevant to his or her strength or weakness. 65 participants completed all the measures of a two-study program (37 participants in study 1 and 28 participants in study 2). At the outset of both studies, participants completed a card sorting task regarding the relevance of self identified (via a brief written narrative) personal strengths and weaknesses to work related problems. In both studies, we primed our participants with their personal strengths and personal weaknesses (counter balance session 1 and session 2) then assessed their self-efficacy for solving work related problems. In study 1 we also assessed the participants' perceived effectiveness at solving work problems. The results indicated that perceived self-efficacy varied as a function of the interaction between personal knowledge and appraisal of the situations. Participants who were primed with their personal strength (weakness) reported the highest (lowest) self-efficacy for the work problems that were relevant to their strength (weakness). The results also indicated that self-efficacy in turn mediated perceived effectiveness to handle work problems over conscientiousness.
\end{abstract}

Keywords: KAPA, idiographic personality assessment, self-efficacy, strengths and weaknesses, conscientiousness

\section{Introduction}

Assessing personality dispositions of current or prospective employees is important in a job setting. Employers view personality assessment as a diagnostic tool because it has predictive value on how employees would perform. For instance, it has been routinely demonstrated that people who display high levels on the trait conscientiousness are in essence better workers than those who do not (Barrick \& Mount, 1991; Jackson et al., 2010; Moon, 2001). What appears to be missing in the extant literature is a complete understanding of what predisposes employees to reach, maintain or develop conscientious behavior at work. Scholars believe that personality assessment of traits on a global level would be better explained by intra-individual variations in points of personal strengths and weaknesses relevant to designated settings (Caprara \& Cervone, 2000; Cervone 2004; Cervone et al., 2008; Orom \& Cervone, 2009). Thus, using models that entail a finite analysis of intra-individual variability is advantageous to further investigate how workers solve problems in a job setting.

\subsection{Personality Assessment and the Contextualization of Traits}

Where the Five Factor Model succeeded in providing descriptions for the five broadest personality traits among individuals, the Big Five (Extraversion, Agreeableness, Openness to Experience, Emotional Stability, and Conscientiousness) merely account for singular traits on an inter-individual, global level, thus discounting for the intra-individual variability of responses to different situations (Beckmann, Wood, Minbashian, 2010; Borsboom, Mellenbergh, Van Heerden, 2003). Situations, or the context in which a behavior takes place, contain different psychological characteristics that reflect meanings and consequences in different manners among individuals (Fleeson, 2007). For example, one employee may approach a review with more anxiety than another employee 
who may remain calm during the same evaluation. Conversely, the same employee who experienced anxiety during the review may remain composed while speaking in public. Essentially, situations are never approached the same way by any two individuals because of intra-individual differences (Cervone, 2004). Personality coherence research showed long since that people display unique profiles of behavior in context (Cervone \& Shoda, 1999; Mishel \& Shoda, 1995) and that such unique profiles can be successfully utilized to remove everyday challenges that impede pursuing one's selected activities (Artistico et al., 2013).

Though certain traits may exhibit more intra-individual stability across situations, the context in which traits are activated varies (Fleeson, 2001). As Fleeson (2001) would suggest, an individual may appear to be highly extraverted in his/her everyday life, yet may encounter strong feelings of needing solitude when asked to prepare for a presentation at work. The variability of traits is stable in the sense we consistently rely on what we know in order to approach situations; however, all situations are distinctive from one another. In addition, all situations entail unique psychological aspects for individuals, thus activating equally unique trait characteristics. We apply these characteristics contextually given the environment or situation, which may change frequently throughout the day. In sum, within-person variability for all traits differs per individuals in everyday behavior, where our actions, thoughts, and feelings are contingent upon the given context (Fleeson, 2001).

The question becomes how do we pinpoint the specific relevancy of traits to different contexts? It would be difficult to answer the question within the Five Factor model approach. The Five Factor model relies on only five traits, each of which lies on a continuum-for example, Introversion/Extraversion, Emotional Stability/Neuroticism - in order to describe people's personality (Barrick \& Mount, 1991). This continuum in turn introduces a plethora of sub-characteristics for each personality trait. For example, an individual who exhibits high levels of neuroticism may be described as anxious, angry, depressed, or insecure, while an individual high in extraversion may be described as talkative, assertive, or sociable (Barrick \& Mount, 1991; Jackson et al., 2010; George \& Zhou, 2001).

Conscientiousness is an especially important trait in the workplace because it predicts job performance, productivity outcomes, and loyalty to the company; however it contains a vast array of sub-characteristics (Jackson et al., 2010; George \& Zhou, 2001; Barrick \& Mount, 1991; Moon, 2001; Cianci, Klein, Seijts, 2010). Examples of conscientiousness sub-characteristics include conformity, organization, goal-orientation, impulse-control, ability to delay gratification, and commitment. Even these sub-characteristics can be explained at a micro-analytic level. Take commitment as an example. One, for instance, could be committed to others, or, duty-striving, as well being commitment to the self, or, achievement-striving (Moon, 2001). A duty-striving commitment may entail staying focused on the upkeep and growth of the company or business. Conversely, achievement-striving would relate to keeping one's job or getting a raise. Herein, the broad definition of conscientiousness - if applied to an employee on a global scale using the Big Five method-may wrongly describe that employee, as it omits both context and the psychological qualities associated with that context.

Solving problems in the work context requires navigating an endless number of situations. Understanding intra-individual and person-to-person variability when reacting to work situations is necessary. A methodological framework that is capable of explaining how personal knowledge can be appraised in different situations may shed light on the way people display higher or lower levels of conscientious behavior. We are aware of one such model (KAPA, see below) used in other contexts (i.e., smoking cessation research, see Cervone et al., 2008) yet not in the work domain, that is, when individuals may display ability to solve work problems.

\subsection{The Knowledge and Appraisal Personality Architecture}

The Knowledge and Appraisal Personality Architecture is a social cognitive theory of personality that utilizes an individual's knowledge and appraisals of situations as a foundation to address the way people solve problems. Unlike previous social cognitive theories (Mishel, 1973 or Bandura, 1986), KAPA postulates personality attributes as applicable locally to the individual person (Cervone, Orom, Artistico, Shadel, \& Kassel, 2007).

Essentially, the KAPA model draws upon an idiographic approach to personality assessment in contrast with the nomothetic approach of the Five Factor Model (Cervone, 2004). Foremost, the KAPA model states all individuals have independent knowledge of how the world works, where this knowledge could be conceived as either generalized or domain-specific (Cervone, 2004). Generalized knowledge may include thoughts of wanting to be a kinder person, or feeling that one likes to spend time alone; domain-specific knowledge may include the belief that one is a team player during sports, or feeling that one is anxious when speaking in front of an audience (Cervone, 2004). Generalized or domain-specific knowledge is idiographic, enduring, and is not always active (Cervone, et al., 2007). Personal points of strength and weakness are the operational way to assess knowledge when appraising people's ability to solve challenges. 
Appraisals are applications of personal knowledge in meaningful evaluations of situations (Cervone, 2004; Cervone, et al., 2008). An example could be that one's shyness will cause embarrassment in an encounter (the self-knowledge), and thus foster anxiety (i.e., I feel awkward), which is the appraisal (Cervone, 2004). Appraisals are based on situations; thus, they vary uniquely within individuals (Cervone, et al., 2008). For instance, the employee who feels a sense of commitment to her job in order to provide for her family may lack that same commitment in a situation evaluated as financially unimportant.

The important component of appraisals is self-efficacy, or one's perceived ability to complete a task in a specific situation (Bandura, 1997). Self-efficacy appraisals are dynamic, as they change according to the influence of self-knowledge in context (Cervone, et al., 2007). The contextual transformation of appraisals embodies the idiosyncratic quality of the person. Consequently, an important function of the KAPA model lies in its ability to measure the saliency of self-efficacy appraisals between a person's qualities and situational challenges they encounter (Cervone et al., 2008).

In sum, the KAPA model has three primary features: (1) KAPA incorporates unique and variable knowledge about the self as it is operationalized by identifying personal points of strength and weakness, (2) KAPA seeks to explains how individuals activate their strengths and weaknesses differently in situations, and (3) KAPA illustrates how the individual makes appraisals about each situation and applies their knowledge accordingly (Cervone et al., 2008).

We capitalized on previous KAPA research and analyzed uniquely activated strengths and weaknesses when solving work related problems. These work related problems were modeled after the trait conscientiousness. In so doing, we also filled a small gap that KAPA research presents, that is, not having included a behavioral measure on how to solve challenges in a job setting.

\subsection{Aims}

When primed with knowledge about the self that is relevant to a particular context, the positive or negative orientation of that knowledge directly contributes to a positive or negative appraisal, respectively, of that situation (Cervone et al., 2008). Previous research has shown support for linking strengths, or positively perceived knowledge, and weaknesses, or negatively perceived knowledge, as they help (hinder) an individual situationally with higher (lower) appraisals of self-efficacy (Cervone et al., 2007; Cervone et al., 2008).

We predict by priming strengths associated with conscientiousness about the self specifically as they help an individual in a work-related situation, the individual's self-efficacy appraisals for solving work problems will be significantly higher. Conversely, we also predict by priming personal weaknesses associated with conscientiousness about the self specifically as they hinder an individual in a work-related situation, the individual's self-efficacy appraisals for solving work problems will be significantly lower. Because the trait conscientiousness successfully predicts effectiveness in the work context, before examining the main hypotheses, we examined whether self-efficacy appraisals could mediate the relationship between conscientiousness and the perceived effectiveness to solve work related problems. We believed this was an important preliminary step to ascertain the salience of self-efficacy in the work context. We tested these predictions by adopting a two-study program.

\section{Study 1}

\subsection{Methods}

\subsubsection{Participants \& Procedure}

44 undergraduate students majoring in business courses were recruited from the subject pool database at Baruch College. Participants signed online for a two-part study and in exchange for their time they received two partial credits toward their course requirements. Previous research on KAPA (i.e., Cervone Shadel \& Jencius, 2001) demonstrated that participants' demographic characteristics are unrelated to the variable of study here; thus, demographics were not collected from our sample. All participants declared to have at least six months of work experience.

37 participants successfully completed two sessions (for reasons unknown, seven participants did not come back to the second session of study). The first session began after participants signed an informed consent document; subsequent tasks included measuring self-knowledge and how it related to solving work problems. A week after the first session, each participant was invited to complete a second session by returning to our lab at exactly the same time. During Session 2, the relationship between personality measures and the ability to solve work problems was measured (see below for a detailed description of both study sessions). For both Session 1 and Session 2, participants worked individually in a lab for approximately one hour, while the experimenter stayed in 
the background prompting about the next task or clarifying any questions they might have. The experimenter did not report any particular difficulty encountered by participants. Participants were debriefed regarding the scope of the study after completion of Session 2.

\subsubsection{Session 1}

In the first session, we asked participants to describe their personality characteristics. Specifically, we asked them to write a personal narrative, in the form of an essay-like paragraph, describing personal characteristics that might help them solve challenging situations in relation to the work context. After a small break, we asked our participants to write personal characteristics that might hinder their ability to solve challenging situations in relation to the work context. At the end of each paragraph, participants were invited to rank their self-reported personality characteristics, and instructed to choose a word or a short sentence to describe their most significant personal point of strength, and most significant personal point of weakness. To assure the selected strength or weakness was the primary choice, we asked participants to briefly explain their selections in one to two sentences. KAPA researchers (see Cervone, 2004 for an overview) have previously validated this step-by-step procedure. The identified personal strength and personal weakness were then used subsequently in the study.

After the personal narrative assessment, we asked participants to complete two card-sorting tasks. The participant needed to assign 24-given potentially challenging problems in a work context (each of which printed on a 2" x 5" index card) to a relevance rating scale that was attached to their personal strength or weakness. The relevancy scale ranged from "helps" to "hinders." For example, one participant identified a personal strength as being gregarious. The word "gregarious" was placed at the very top of the scale; below were the numbers 1 through 9 and thus nine different spaces for participants to sort the 24 work-related situations physically on the scale (see Figure 1).

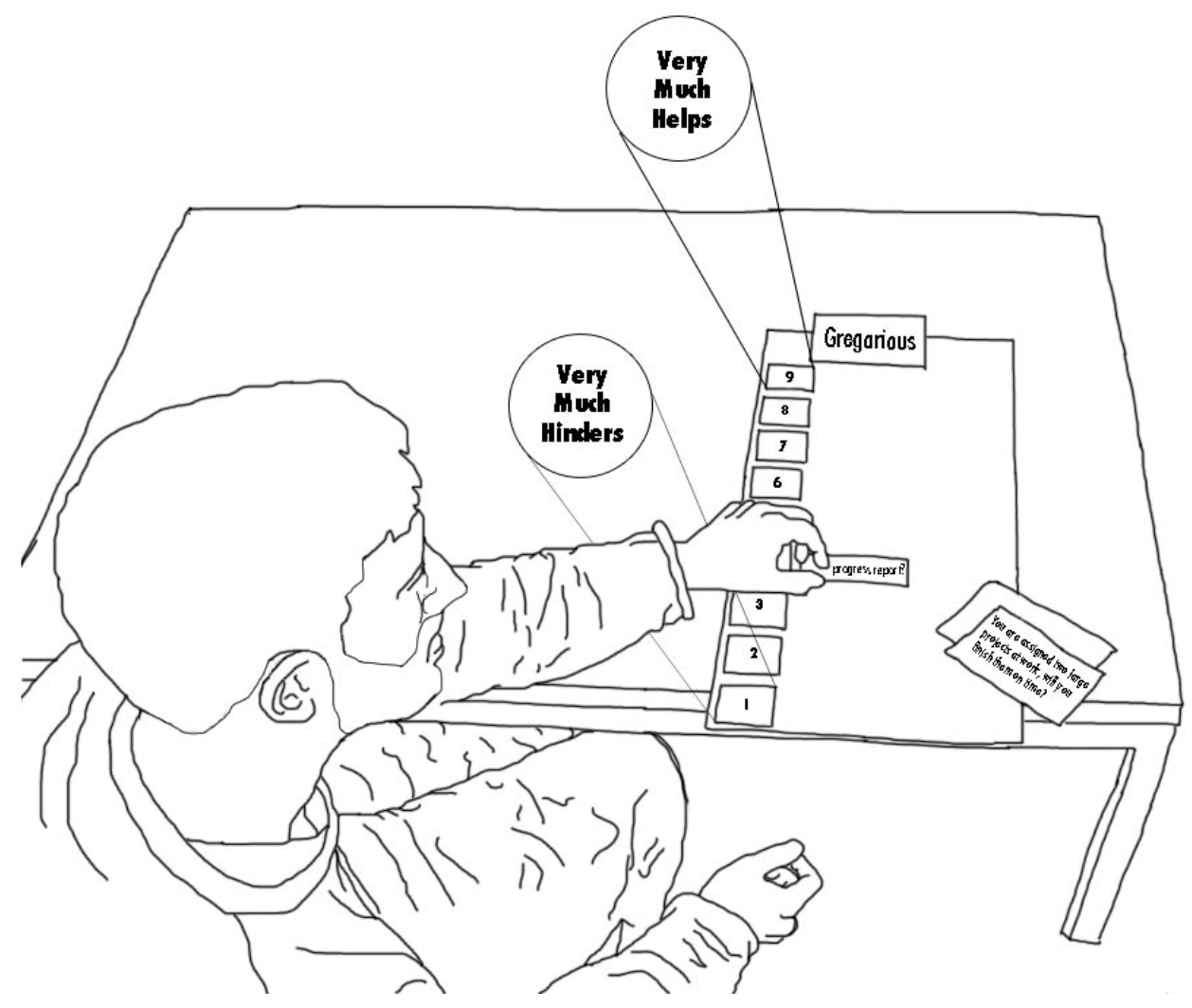

Figure 1. The paper-scale card-sorting task participants completed at the outset of the study

Consistent with previous research on KAPA a card that is placed from 7 to 9 would be considered a "help" appraisal; 4 to 6 would be neutral, and 1 to 3 would be considered a hindrance.

Thus, the goal of the first sorting task was to determine the relevancy of the personal strength for the appraisal of work-related problems. The goal of the second card-sorting task was to determine the relevancy of the personal 
weakness for the appraisal of work-related problems. The order of the presentation of the two card sorting tasks was counter balanced. The order of presentation produced null results when measuring its effect on self-efficacy appraisals $(t(35)=-0.55 ; p>.59)$.

To study the effects of priming procedures of personal knowledge (strengths and weaknesses) on the self-efficacy for solving work related problems, we administered a "memory test" story at the outset of participants completing the main dependent variable of the study, which was measured by a questionnaire about their perceived self-efficacy for solving work-related problems. The story depicted a fictional character who possessed the ideographically-identified participant's characteristics. The participant's task was to listen to the story (a paragraph in length), read it, and finally answer a brief questionnaire about the personality characteristics of the main character, where these characteristics were modeled after participant's previously self-reported strengths and weaknesses. Throughout the story, each personal strength or weakness was repeated seven times using synonyms retrieved from Webster's dictionary. One half of the sample was primed first with their personal strength (then in the second session with the weakness), while the other half was primed first with their weakness (then in the second session with the strength). No effects were produced by the order of presentation of the story $(t(35)=0.60 ; p>.55)$. Participants' performance on the priming procedures was exceptionally high $(M=5.04 ; S D=1.26$, range from 1 to 7$)$. These results suggest that the priming procedure was well received.

The subsequent and final task for Session 1 was to complete two measures, which were related to the main dependent variables of the study. The first measure was about appraisals of self-efficacy for solving work-related problems. The second measure related to perceived problem-solving ability, and specifically corresponded with the same 24 work-related problems participants were asked about during the card-sorting task. At the end of the first session, the experimenter scheduled the second session to take place one week from Session 1.

\subsubsection{Session 2}

Participants began the second session by undergoing the same priming procedure that was presented during Session 1; however, if during Session 1 participants were primed with their personal strength (weakness), in Session 2 they were primed with their personal weakness (strength). After the priming personality assessment was completed, participants responded to the two main dependent variables of the study. Specifically, participants answered the same questions from Session 1 about their perceived self-efficacy for solving work related problems, and then the other set of questions to measure their perceived effectiveness to solve such work problems. To ensure our hypothesis testing, participants answered the two main dependent variables both with and without the effect of priming. Because the ability of the KAPA framework priming procedures was demonstrated previously, we were able to witness the effect of the personal strength (weakness) when primed or not primed. The final task for participants was to fill out the 120-item version of the IPIP in order to measure the effect of trait conscientiousness.

\subsection{Measures}

\subsubsection{Self-Efficacy and Perceived Effectiveness to Solve Work Problems}

The Self-Efficacy and Perceived Effectiveness to Solve Work Problems Questionnaire is a 24-item paper and pencil measure that depicts work related problems. The work related problems were adapted from the trait conscientiousness as developed by the International Personality Item Pool (IPIP). The conscientiousness items were rendered in behavioral measures. For example the original item of the IPIP "I am always prepared IPIP," became "Whenever I am assigned a presentation at work, I am always prepared"; the item "Carry out my plans" became "If I plan on writing individual progress reports on my subordinates, I will follow through" (see the Appendix for the full list of items).

The participant's task was to answer on scale (from 1-not at all confident to 10-absolutely confident) with respect to his/her confidence to solve the challenges that were portrayed in the 24 situations. The next set of questions asked participants about their perceived effectiveness in resolving the 24 situations. Participants responded on a likert type scale ranging from (1-not at all to 7-very much so). The reliability analysis showed good results for the questionnaire for both self-efficacy $(\alpha=.90$ in Session 1 and $\alpha . .96$ in Session 2) and perceived effectiveness $(\alpha=.92$ in Session 1 and $\alpha .95$ in Session 2).

\subsubsection{The International Personality Item Pool (IPIP)}

The IPIP is a 120-question measure designed as a representation of the NEO-PI-R. Specifically, the IPIP is a short-form personality assessment designed to capture the Big Five personality traits among individuals. Participants responded on a paper version of the IPIP using a five-point scale to describe their agreement with 
the statement presented (from 1-very inaccurate to 5-very accurate). We utilized only the trait conscientiousness composite scores in the study for the mediation analysis. The measure of trait conscientiousness reached a satisfactory internal reliability $(\alpha=.85)$.

\subsection{Results}

\subsubsection{Descriptive Case and Sample Analysis}

The sample provided a variable typology of personal strengths viewed as helpful to solving work related problems. Even if participants' personal strengths were semantically similar with each other, no two participants worded their personal strength exactly the same. Perhaps more importantly when looking at situations that were chosen as relevant to their personal strengths, the constellation of participant's knowledge and appraisal varied from person to person. Similar descriptive findings were accounted for by looking at participants' responses describing their personal points of weakness and the appraisal of their weaknesses for the situation (see Table 1).

Table 1. Study 1 Uniquely Identified Personal Strengths and Weaknesses Together with the Situations in which They Were Relevant or Irrelevant

\begin{tabular}{|c|c|c|c|c|}
\hline Case & Strength & Weakness & $\begin{array}{l}\text { Situations* where strength } \\
\text { helps and weakness is } \\
\text { neutral }\end{array}$ & $\begin{array}{l}\text { Situations where } \\
\text { weakness hinders and } \\
\text { strength is neutral }\end{array}$ \\
\hline 1 & Resourceful & Frantic & $1,3,22$ & $2,14,20$ \\
\hline 2 & Methodical & Stationary & $1,18,24$ & $3,10,11$ \\
\hline 3 & Considerate & Timid & $3,5,7,8,11,12,13,18$ & $2,6,9,10,16,19,20,21$ \\
\hline 4 & Dawdler & Lazy & $1,5,13,15,16,17$ & 2,8 \\
\hline 5 & Motivated & Manic & $1,5,15$ & $2,3,9,13$ \\
\hline 6 & Interested & Distracted & $13,18,22$ & $4,7,8,9,10,11,12,24$ \\
\hline 7 & Regular & Dallying & $1,2,3,20$ & $5,6,7,10,11,12,24$ \\
\hline 8 & Inventive & Irritated & 2,18 & 11,13 \\
\hline 9 & Enthusiastic & Procrastinate & $7,13,16$ & $1,3,4$ \\
\hline 10 & Hardworking & Impatient & $5,9,11,22$ & $1,2,3,4,6,7,20$ \\
\hline 11 & Keenly & Livid & $6,10,22,23$ & $9,12,21$ \\
\hline 12 & Ready to Work & Distracted & $5,6,7,22$ & 20,21 \\
\hline 13 & Exact & Young & 11,12 & $2,3,17$ \\
\hline 14 & Meticulous & Nervous & $7,20,23$ & 4,12 \\
\hline 15 & Unbiased & Anxious & $4,5,7,20$ & $2,3,11$ \\
\hline 16 & Well-organized & Indifferent & $16,18,19,20$ & $1,3,15$ \\
\hline 17 & Good structure & Serene & $1,11,12$ & $2,3,5$ \\
\hline 18 & Attentive & Impeding & $6,10,15$ & $1,2,4,14,18,20$ \\
\hline 19 & Effective & Tired & $5,10,12$ & $6,17,23,24$ \\
\hline 20 & Exact & Flawless & $2,6,7,11,18$ & $13,22,23$ \\
\hline 21 & Decisive & Impulsive & $8,15,16,18,19,20,23$ & $2,4,6,24$ \\
\hline 22 & Steady & Exposed & $5,8,16,18$ & $6,7,17$ \\
\hline 23 & Intent & Slow & $4,6,8,20,22$ & $2,7,12,15,17$ \\
\hline 24 & Dependable & Dazed & $8,15,19,24$ & $3,10,13,17,20$ \\
\hline 25 & Dedicated & Lazy & $3,4,6,10,11,13,15,17,18,19,22$ & $5,14,16,20,21,23,24$ \\
\hline 26 & Obedient & Panicky & $11,14,18,24$ & $2,5,6$ \\
\hline 27 & Purposeful & Lazy & $8,15,18$ & $2,4,21,24$ \\
\hline
\end{tabular}




\begin{tabular}{lllll}
\hline 28 & Vivacious & Sluggish & $7,18,21$ & $1,5,17,23$ \\
29 & Systematic & Sheepish & $1,5,9,24$ & $2,3,4,20,23$ \\
30 & Engaged & Tiresome & $13,14,20$ & $1,8,16,17,23$ \\
31 & Faultless & Lazy & $1,4,8$ & $2,3,5$ \\
32 & Ready & Jumble & $1,5,6,11,12,24$ & $2,4,7$ \\
33 & Concentrated & Lordly & $5,10,23$ & $1,22,24$ \\
34 & Prepared & Exceptional & $1,3,8,16$ & $2,5,11,18$ \\
35 & Optimistic & Dragging feet & $11,22,24$ & $2,5,9$ \\
36 & Ordered & Daydreamer & $1,3,5,7,18$ & $2,6,8,13,24$ \\
37 & Committed & Sluggish & $2,5,13,21$ & $3,20,24$ \\
Central Tendency for Situation (N) & & $M=4 ; S D=1.67$ \\
\hline
\end{tabular}

*Nominal descriptions of situations are fully reported in Appendix.

In addition, three personality experts with degrees in social and personality psychology rated similarities among semantic meanings between reported strengths and weaknesses. The average level of similarities among personal attributes was assessed on a 9 point scale (ranging from 1-absolutely different to 9-absolutely the same), and the experts' rating average was $M=2.15 ; S D=0.55$.

2.3.2 Self-Efficacy Mediation Analysis between Trait Conscientiousness and Perceived Effectiveness for Solving Work Problems

We adopted the suggested mediation procedure, as outlined in Baron and Kenney (1986), to test the mediation of self-efficacy appraisals (SE) between trait conscientiousness (TC) and perceived effectiveness for solving work problems (PESWP). Importantly in this analysis, SE scores were gauged as a total score without differentiating between points of strength and weakness. SE and TC levels were correlated $(r(35)=0.57, p<.001)$. TC levels were also significantly correlated with measures of PESWP $(r(35)=0.53, p<.001)$. SE and PESWP were also correlated $(r(35)=0.87, p<.001)$. After entering in the regression analysis of both TC and SE to predict PESWP, $\mathrm{TC}$ was no longer a significant predictor $(t(35)=1.55$, ns) while SE was $(t(35)=7.98, p<.001)$. These results support the notion that SE is a mediator for PESWP (SOBEL Test $=1.48, S D=0.07, p=.14$ ).

\subsubsection{Personal Points of Strengths and Weaknesses \& Problem-Solving}

To test our main prediction we employed a fully within subject $2 \times 2$ design where the two independent variables were strength (primed and not primed) and weakness (primed and not primed). Importantly, these personal points of strength and weakness were independent from each other, that is, we contrasted only situations in which the strength (weakness) helped (hindered), but the weakness (strength) was neutral. The main dependent variable was self-efficacy appraisal. The interaction was significant $F(1,36)=7.31, p<.01 ; \quad{ }^{2}=.169$ even after controlling for the trait conscientiousness $(F(1 ; 35)=4.74, p<.05)$. However the effect $F(1,36)=84.39, p$ $<.001 ; \eta^{2}=.60$ was driven by the personal strength (primed $M=8.33, S D=1.29$; not primed $M=7.83, S D=$ 1.51). There were no differences $(F(1,36)=.788, \mathrm{~ns})$ in the appraisals of self-efficacy with or without weakness priming (primed $M=6.47, S D=1.62$; not primed $M=6.67, S D=1.55$ ). Mean levels of self-efficacy appraisals for relevant points of strength and weakness are also reported in Figure 2. 


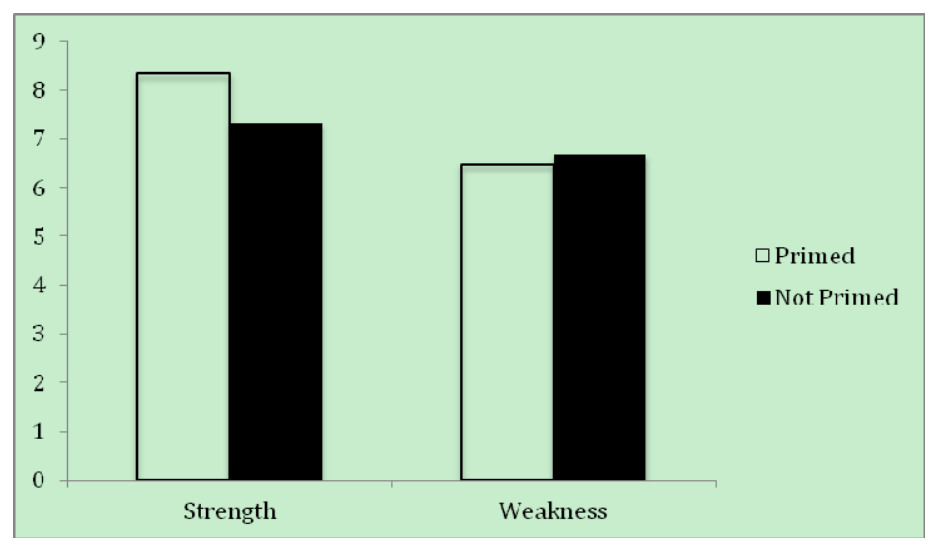

Figure 2. Average levels of self-efficacy appraisals for situations in which the strength (weakness) is relevant (not relevant) and the weakness is not relevant (relevant)

Consistent with previous research on KAPA (see Cervone et al., 2008 for instance), we found a main effect ( $t(36)$ $=7.34, p<.001$ ) by type of personal knowledge, that is, participants scored higher on levels of self-efficacy appraisals when personal points of strength helped, compared to personal points of weakness that hindered in situations. Also, self-efficacy appraisals were not different from Session $1(M=6.99, S D=1.48)$ or Session $2(M$ $=7.19, S D=1.44)$ when neither strength nor weakness were relevant to solve the work problems $(t(36)=-1.75$, $p>.09)$.

\subsection{Conclusion}

The results indicated that self-efficacy appraisals varied as function of knowledge and appraisal activation. As reported in Table 1, participants greatly differ from one another regarding their personal points of strength and weakness (knowledge), and where their knowledge became salient. Self-efficacy mediated the relationship between trait conscientiousness and their perceived effectiveness to solve challenges at work. The KAPA model in turn explained self-efficacy appraisals: When personal strength was relevant to the work context, individuals displayed high levels of self-efficacy appraisals than when not relevant; when a weakness hindered their ability to solve problems, self-efficacy appraisals were low. The interaction between personal knowledge and the priming procedure was also significant, but the main effect for priming personal points of weakness was not significant.

\section{Study 2}

The sample in Study 1 was small and highly homogenous with people majoring in business. We wondered if replication of the study (another sample of undergraduates drawn from the same population) would be able to produce the same results. As personal weakness did not show a main effect in Study 1, we replicated the same experimental design with a larger variety of situations. We asked four industrial and organizational psychologists to ample the situational repertoire by designing a more comprehensive array of behavioral challenges that relate to conscientiousness in the work place.

We suspected by employing a larger variety of situations, individuals would activate appraisals of personal weaknesses. We then hypothesized the effects of priming a personal weakness would produce negative appraisals of situations with a significant effect. We also included measures of perceived stress to rule out the possibility that our findings varied as a function of other psychosocial mechanisms.

\subsection{Methods}

\subsubsection{Participants, Session 1 and Session 2}

The methodology for Study 2 was very similar to the methodology of Study 1 (see Figure 3 ). 


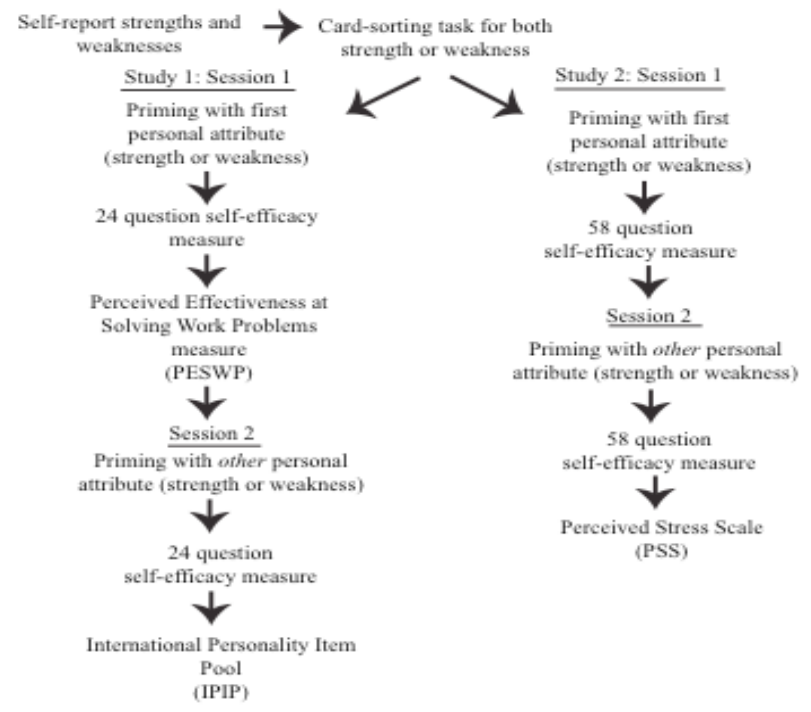

Figure 3. Similarities and differences between Study 1 and Study 2.

Participants were recruited from the subject pool database at Baruch College; they were undergraduate students majoring in business courses. Again, all participants declared to have at least six months of work experience and, in exchange for their time, received two credits of research experience toward their class requirements.

28 participants successfully completed two sessions, one week apart (37 participants were initially recruited, but nine participants did not come back to complete the study). For both Session 1 and Session 2, participants worked individually in a lab for approximately one hour (without particular difficulty to report). All participants were debriefed regarding the scope of the study at the end of Session 2.

In the first session, participants were asked to describe their personality characteristics in the same manner as in the first study (see Study 1, Session 1 above). Participants also completed a "memory task" situated in a work context, similar to the memory task given in Study 1. The manipulation check for the priming story produced satisfactory results $(M=6.29, S D=0.87$, max possible was 7 points). As we were not able to find a main effect for weaknesses in the first study, the self-efficacy measure administered during the Study 2 featured 58 work-related situations (rather than 24 situations) to maximize situational variability. These 58-work related situations were qualitatively similar to the original 24 situations given in the first study.

If participants were primed with their personal weakness during Session 1, they were then primed with their personal strength during Session 2. Because the results of Study 1 demonstrated that self-efficacy appraisals mediate the relationship between trait conscientiousness and perceived effectiveness to solve work problems, participants responded to only one main dependent variable of the study, which was self-efficacy. Similar to Study 1, to ensure our hypothesis testing, participants answered the self-efficacy questionnaire both with and without the effect of priming. To rule out the possibility that the results were due to other type of individual differences, we measured participant's perceived stress, as perceived stress could be relevant to handling work problems.

\subsection{Measures}

\subsubsection{Work Problem Self-Efficacy Questionnaire (58-WPSEQ)}

We expanded the situations by asking four Industrial and Organizational psychologists to discuss potential challenging situations in which a high dose of conscientiousness could be necessary to resolve problems. They worked first independently, and then exchanged their input to finally produce 58 situations that tapped into a large variety of work problems. The purpose of increasing the number of situations was to further activate participants' knowledge, thus strengthening the effect of the personal strength (weakness) when primed. By increasing the effect of the primed personal strength (weakness), we hoped to find a significant main effect for primed personal points of weakness, as we were unable to in Study 1.

The 58-WPSEQ was designed in order to assess confidence in work-related situations. For instance, participants were given hypothetical scenarios such as simultaneously being assigned two large projects at work, or shortening one's lunch break in order to finish a task, and were then asked to gauge their confidence in being 
able to complete these tasks. Participants could answer on a scale from 1-certain I could not do it, to 10-certain I could do it, where 5 was neutral. While questions varied as to specific subject matter, all questions were similar to the 24 job-centered self-efficacy questions given in Study 1, and focused on self-regulation, commitment, goal-orientation, and ability to plan ahead, all of which are important factors of conscientiousness. The reliability analysis showed satisfactory results ( $\alpha=0.94$ in Session $1 ; \alpha=0.97$ in Session 2).

\subsubsection{Perceived Stress}

Perceived stress was assessed with the Perceived Stress Scale (PSS) developed by Cohen \& Williamson (1988). PSS consists of four questions which rate an individual's subjective perception of stress during the last month. Participants' answers are recorded based on a scale that ranges from "never" to "very often" experienced stress. We assessed the internal consistency $(\alpha=0.73)$ of the scale in our sample.

\subsection{Results and Conclusion}

Similarly to Study 1, the constellation of participant's knowledge and appraisal varied from person to person (see Table 2).

Table 2. Study 2 Uniquely Identified Personal Strengths and Weaknesses Together with How Many Situations Participants Judged Relevant or Irrelevant

\begin{tabular}{|c|c|c|c|c|}
\hline Case & Strength & Weakness & $\mathrm{N}^{*}$ & $\mathrm{~N}$ \\
\hline 1 & Self-motivated & Spontaneous & 33 & 11 \\
\hline 2 & Organized & Discouraged & 9 & 9 \\
\hline 3 & Careful & Lazy & 9 & 12 \\
\hline 4 & Open-minded & Feeble & 17 & 6 \\
\hline 5 & Committed & Boring & 20 & 11 \\
\hline 6 & Particular & Introverted & 11 & 10 \\
\hline 7 & Through & Negative & 4 & 6 \\
\hline 8 & Reasonable & Unmotivated & 6 & 16 \\
\hline 9 & Logical & Relaxed & 4 & 12 \\
\hline 10 & Enthusiastic & Unmotivated & 9 & 4 \\
\hline 11 & Efficient & Vague & 6 & 10 \\
\hline 12 & Responsible & Boring & 7 & 18 \\
\hline 13 & Persistent & Unsure & 9 & 24 \\
\hline 14 & Responsible & Undependable & 16 & 4 \\
\hline 15 & Efficient & Stubborn & 8 & 6 \\
\hline 16 & Prepared & Irresponsible & 8 & 8 \\
\hline 17 & Efficient & Careless & 6 & 12 \\
\hline 18 & Responsible & Irresponsible & 13 & 7 \\
\hline 19 & Precise & Stubborn & 18 & 3 \\
\hline 20 & Precise & Undependable & 14 & 10 \\
\hline 21 & Ambitious & Careless & 5 & 8 \\
\hline 22 & Careful & Unreliable & 3 & 5 \\
\hline 23 & Exact & Boring & 7 & 8 \\
\hline 24 & Committed & Careless & 14 & 6 \\
\hline 25 & Honest & Dishonest & 9 & 11 \\
\hline 26 & Committed & Reserved & 6 & 5 \\
\hline 27 & Organized & Shy & 8 & 11 \\
\hline
\end{tabular}




\begin{tabular}{|c|c|c|c|}
\hline 28 & Easily Bored & 6 & 11 \\
\hline \multicolumn{2}{|c|}{ Central Tendency for Situation (N) } & $\mathrm{M}=10.18 ; \mathrm{SD}=6.32$ & $\mathrm{M}=9.43 ; \mathrm{SD}=4.56$ \\
\hline
\end{tabular}

*Situations in which strength (weakness) helps (hinders) and weakness (strength) is neutral

However, the average number reported by each case was sensibly higher than those reported in Study 1 . Three personality experts rated similarities among the semantic meanings between the reported strengths and weaknesses. The average level of similarities among personal attributes was assessed on a 9 point scale (ranging from 1-absolutely different to 9-absolutely the same), and the experts rating average was $M=1.92 ; S D=1.26$. Measures of perceived stress were not significantly correlated with the measures of self-efficacy appraisals (average $r(26)=-0.27, p>.10$ ).

To test our main prediction, we employed a fully within subject $2 \times 2$ design where the two independent variables were strength (primed and not primed) and weakness (primed and not primed). We contrasted situations in which the strength (weakness) helped (hindered), but the weakness (strength) was neutral. The main dependent variable was self-efficacy appraisal. The interaction was significant $F(1,27)=26.08, p<.001 ; \eta^{2}$ $=.49)$. Both personal strength $(t(1,26)=4.23, p<.001)$ and weakness $(t(1,26)=-2.33, p<.03)$ were higher (strength) or lower (weakness) when primed than when not primed. Mean levels of self-efficacy appraisals for relevant points of strength and weakness are reported in Figure 4.

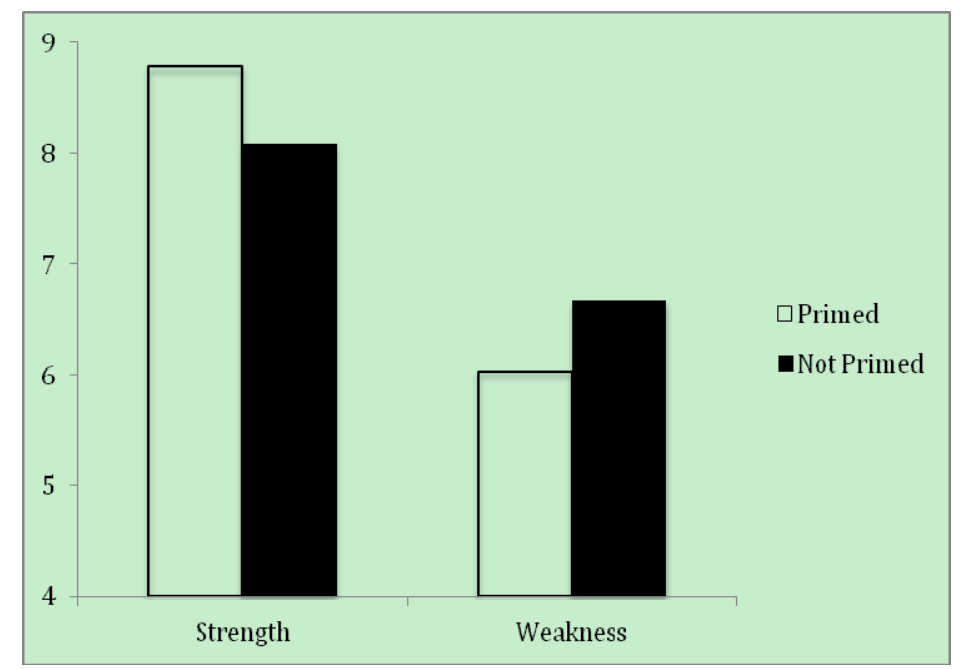

Figure 4. Average levels of self-efficacy (Study 2) for situations in which the strength (weakness) is relevant (not relevant) and the weakness is not relevant (relevant)

We found a main effect $(t(26)=9.29, p<.001)$ by type of personal knowledge, that is, participants scored higher on levels of self-efficacy appraisals when personal points of strength were seen as helpful, as opposed to when personal points of weakness were seen as a hindrance. Also, total self-efficacy appraisals were not statistically different $(t(27)=-1.90, p>.07)$ from Session $1(M=7.46, S D=0.89)$ or Session $2(M=7.67, S D=.96)$. In conclusion, the results of Study 2 fully supported our hypotheses.

\section{General Discussion}

Our research sought to isolate situations where personal attributes of perceived strengths and weaknesses associated with conscientious behavior, via priming, would help or hinder individuals' self-efficacy appraisals and a person's effectiveness at solving work-related problems. By priming knowledge about the self, essentially, promoting the relevancy of knowledge as it applies in specific contexts, we hoped to promote either higher or lower appraisals of situations; ergo, this would be represented as an increase or decrease in self-efficacy. The results largely supported our hypotheses.

By utilizing the KAPA model whilst applying it specifically to the workplace, generalizations about how to promote conscientious behavior can be made in a way not possible by the Five Factor Model. In focusing on the 
mediation of self-efficacy between conscientiousness and effectiveness at solving work problems, conscientiousness-related behavior can be promoted by priming workplace-relevant strengths about the self, thus increasing self-efficacy and also increasing effectiveness in the workplace. Furthermore, behavior that is seen to be the opposite of conscientiousness can be avoided by improving upon one's weakness about the self in relation to the work context. In general, self-efficacy acts as a mediator between trait conscientiousness and effectiveness at solving work-related problems, and the effect of the KAPA model is still significant even with a covariance analysis of the trait conscientiousness.

When personal, relevant strengths were primed, self-efficacy appraisals increased; when personal, relevant weaknesses were primed, self-efficacy appraisals decreased. For both strengths and weaknesses, when neither ones were primed, mean scores of self-efficacy appraisals were about the same. Certainly, the research supports the notion that all individuals have strengths and weaknesses where this knowledge can be used contextually to anticipate unique appraisals of situations, as well as the idea that in some situations personal characteristics are just irrelevant. In the case of weaknesses, improvement must be tailored to the person who is presenting lacunas in important work functions, keeping in mind that such shortcomings may be relevant to some yet not all work functions.

As a first attempt at using KAPA in the work context, the study contains inherent limitations. For one, the samples were small, however, the effects were sufficiently robust in both studies to conclude KAPA can be safely adopted to explain conscientious behavior in a job setting. The individuals in our research were still young (college students), however their approach to the work domain was significant. Participants declared at least six months of work experience and their major was in business. Business students are typically versed in the work context.

In the near future, we auspicate that KAPA will be used on a more heterogeneous sample of participants with a more diversified work experience alongside with enlarging the scope of the study. This could be accomplished perhaps by partnering with a company that offers assessment, training and development for its employees. One could prime employees with personal strengths not only in a brief experimental setting, yet also by drawing a longitudinal methodology to boost their effectiveness in the workplace. Here, we could use the KAPA model to gauge how priming procedures foster employees' appraisals of self-efficacy to resolve problems at work within a conscientious mindset. Supervisors could attempt to increase performance by sincerely acknowledging an employee's personal strengths before assigning a difficult or tedious task. Continual recognition of conscientiousness-related strengths throughout completion of the task would ensure maintenance of high levels of self-efficacy within the employee, where the evaluation of the KAPA model in the work context could then be coupled with objective measures of performance in a job setting (i.e., supervisor's evaluations or sales).

Limitations regarding extending these findings into the real world relate to maintaining objectivity within supposed evaluations or sales comparisons; great effort would be required from the supervisor to remain cognizant of and prime each employee's unique personal strengths, while avoiding activating personal weaknesses. Avoiding personal weaknesses presents further limitation for supervisors, as it casts criticism in an unfavorable light; rather, supervisors must take care not to prime their employees with negative feedback first. While not all supervisors may have the patience, care, or managerial skills necessary to focus on promoting the strengths of their employees, the idea is that by increasing conscientious-related behavior, such as commitment, motivation, and goal-striving, one could increase performance and productivity in the workplace.

In conclusion, the KAPA model offers a more idiographic approach to personnel development, and presents useful implications for the job setting and employee performance. The present study demonstrates a method to promote conscientious behavior geared toward solving problems in the workplace, while still accounting for the multifaceted nature of context and it's psychological influence on traits.

\section{References}

Artistico D., Pinto A. M, Douek J., Black J., \& Pezzuti L. (2013). The value of removing daily obstacles via everyday problem-solving theory: Developing an applied novel procedure to increase self-efficacy for exercise. Front Psychology, 4(20). http://dx.doi.org/10.3389/fpsyg.2013.00020

Bandura, A. (1986). Social foundation of thoughts and Action: A social Cognitive Theory. Englewood Cliffs, NJ: Prentice Hall.

Bandura, A. (1997). Self-efficacy: The exercise of control. New York: Freeman and Company.

Baron, R. M., \& Kenny, D. A. (1986). The moderator-mediator variable distinction in social psychological research: Conceptual, strategic, and statistical considerations. Journal of Personality and Social Psychology, 


\section{$51,1173-1182$.}

Beckman, N., Wood, R., \& Minbasian, A. (2010). It depends how you look at it: On the relationship between neuroticism and conscientiousness at the within- and the between-personal levels of analysis. Journal of Research in Personality, 44, 593-601. http://dx.doi.org/10.1016/j.jrp.2010.07.004

Barrick, M., \& Mount, M. (1991). The Big Five Personality Dimensions and Job Performance: A Meta-Analysis. Personnel Psycholgy, 44, 1-6. http://dx.doi.org/10.1111/j.1744-6570.1991.tb00688.x

Borsboom, D., Mellenbergh, G. J., \& Van Heerden, J. (2003). The theoretical status of latent variables. Psychological Review, 110, 203-219. http://dx.doi.org/10.1037/0033-295X.110.2.203

Caprara, G. V., \& Cervone, D. (2000). Personality: Determinants, dynamics, and potentials. Cambridge, UK: Cambridge University Press.

Cervone, D. (2004). The architecture of personality. Psychological Review, 111, 183-204. http://dx.doi.org/10.1037/0033-295X.111.1.183

Cervone, D., Orom, H., Artistico, D., Shadel, W., \& Kassel, J. (2007). Using a Knowledge-and-Aprraisal Model of Personality Architecture to Understand Consistency and Variability in Smokers' Self-Effiacy Appraisals in High-Risk Situations. Psychology of Addictive Behaviors, 21, 44-54. http://dx.doi.org/10.1037/0893-164X.21.1.44

Cervone, D., Caldwell, T., Fiori, M., Orom, H., Shadel, W., Kassel, J., \& Artistico, D. (2008). What Underlies Appraisals? Experimentally Testing a Knowledge-and-Appraisal Model of Personality Architecture Among Smokers Contemplating High-Risk Situations. Journal of Psychology, 76, 929-968.

Cervone, D., \& Pervin, L. A. (2010). Personality: Theory and Research (11th ed.). United States of America: John Wiley \& Sons, Inc.

Cervone, D., Shadel, W. G., \& Jencius, S. (2001). Social-cognitive theory of personality assessment. Personality and Social Psychology Review, 5, 33-51.

Cianci, A. M., Klein, H. J., \& Seijts, G. H. (2010). The Effect of Negative Feedback on Tension and Subsequent Performance: The Main and Interactive Effects of Goal Content and Conscientiousness. Journal of Applied Psychology, 95, 618-630. http://dx.doi.org/10.1037/a0019130

Cutrona, C. E., \& Russell, D. (1987). The provisions of social relationships and adaptation to stress. In W. H. Jones, \& D. Perlman (Eds.), Advances in personal relationships (Vol. 1, pp. 37-67). Greenwich, Conn.: JAI Press.

Fleeson, W. (2001). Toward a Structure- and Process-Integrated View of Personality: Traits as Density Distributions of States. Journal of Personality and Social Psychology, 80, 1011-1027. http://dx.doi.org/10.1037/0022-3514.80.6.1011

Fleeson, W. (2007). Situation-Based Contingencies Underlying Trait-Content Manifestation in Behavior. Journal of Personality, 75, 825-861. http://dx.doi.org/10.1111/j.1467-6494.2007.00458.x

George, J. M., \& Zhou, J. (2001). When Openness to Experience and Conscientiousness Are Related to Creative Behavior: An Interactional Approach. Journal of Applied Psychology, 86, 513-524. http://dx.doi.org/10.1037/0021-9010.86.3.513

Jackson, J., Wood, D., Bogg, T., Walton, K., Harms, P., \& Roberts, B. (2010). What do conscientious people do? Development and validation of the Behavioral Indicators of Conscientiousness (BIC). Journal of Research in Personality, 44, 501-511. http://dx.doi.org/10.1016/j.jrp.2010.06.005

Mischel, W. (1973). Toward a cognitive social learning reconceptualiza-tion of personality. Psychological Review, 80, 252-283. http://dx.doi.org/10.1037/h0035002

Mischel, W., \& Shoda, Y. (1995). A cognitive-affective system theory of personality: Reconceptualizing situations, dispositions, dynamics, and invariance in personality structure. Psychological Review, 102, 246-286. http://dx.doi.org/10.1037/0033-295X.102.2.246

Moon, H. (2001). The Two Faces of Conscientiousness: Duty and Achievement Striving in Escalation of Commitment Dilemmas. Journal of Applied Psychology, 86, 533-540. http://dx.doi.org/10.1037/0021-9010.86.3.535 


\title{
Appendix
}

\author{
24 Work Related Problems that were Modeled After the Trait Conscientiousness \\ IPIP Question Number / Self-Efficacy Scale Question Number*
}

5. Complete tasks successfully. / 18. My supervisor asked that I make sure my tasks are finished thoroughly this week. I make sure I am exact with my tasks.

10. Like to tidy up. / 7. I pay attention to detail in others' work tasks.

15. Keep my promises. / 9. The first day at work after a two week vacation. I will not find it difficult to get down to work.

20. Work hard. / 11. At work, I set for myself high goals and expect to accomplish them.

25. Am always prepared. / 15. Whenever I am assigned a presentation at work, I am always prepared.

30 (R). Jump into things without thinking. / I start a work project. I will avoid starting with without planning ahead.

35. Excel in what I do. / 20. I don't hand in a project at work until I know that it is perfect.

40 (R). Often forget to put things back in their proper place. / 6. The deadline for a new project at work is unclear. I will plan ahead.

45. Tell the truth. / 22. I urge coworkers away from shortcuts and encourage them to do things by protocol.

50. Do more than what's expected of me. / 8. I am assigned some extra tasks. I get them done right away, so I can focus on the more routine activities.

55. Carry out my plans. / 23. If I plan on writing individual progress reports on my subordinates I will follow through.

60 (R). Make rash decisions. / 16. When completing a task at work, I pay full attention to detail.

65. Handle tasks smoothly. / 4. I am unexpectedly assigned extra work for the day. I accomplish my work on time.

70 (R). 1. I have plenty of work that can only be done by shortening my lunch break. I avoid leaving work undone until the next day.

75. Break rules. / 21. I always think about the consequences before tackling a problem in a new way.

80 (R). Do just enough work to get by. / 10. Even when I don't like the work I'm doing, I avoid doing just enough work to get by.

85. Waste my time. / 24. I avoid things at work that are not productive and that cause me to waste my time.

90 (R). Rush into things. / 19. I have each day lined up according to a plan.

95. Know how to get things done. / 3. At work I won't postpone the unpleasant tasks.

100 (R). Leave my belongings around. / 17. At work, I am sure to complete miscellaneous tasks right way to get back to my work as quickly as possible.

105 (R). Break my promises. / 12. New things come up that require my attention. I finish what I start.

110 (R). Put little time and effect into my work. / 5. I am careful to avoid making mistakes in my work.

115 (R). Have difficulty starting tasks. / 14. There are a few things to do at work that I don't like to do. There is plenty of time before they are due; I avoid needing a push to get started.

120 (R). Act without thinking. / 13. There are unusual distracting situations at work and I have not slept well. I still avoid making mistakes.

*(R) means the question is reversely scored

\section{Copyrights}

Copyright for this article is retained by the author(s), with first publication rights granted to the journal.

This is an open-access article distributed under the terms and conditions of the Creative Commons Attribution license (http://creativecommons.org/licenses/by/3.0/). 